\title{
La venta de cargos de Indias en tiempos de Olivares: el conde de Castrillo*/
}

\section{The Sale of Offices in the Indies in the Days of Olivares: the Count of Castrillo}

\section{Francisco Gil Martínez}

ORCID iD: http://orcid.org/0000-0002-5121-2316

Universidad de Almería

En la década de 1630, Olivares puso en marcha una campaña de ventas de oficios de proporciones desconocidas hasta entonces. El presidente del Consejo de Indias, el conde de Castrillo, fue el encargado de negociar personalmente la gran mayoría de las operaciones relativas a América. Analizamos el entramado administrativo mediante el cual se tramitaron las ventas y sus implicaciones políticas.

Palabras Clave: Venalidad; Oficios; Castrillo.

In the 1630 decade, Olivares began a disproportionate campaign of sales of public offices. The president of the Indias Council, the Count of Castrillo, was the person in charge for the sales related with America. We analyze the administrative scheme used for the sales and his politics consequences.

KeYwords: Venality; Offices; Castrillo.

Copyright: (C) 2017 CSIC. Este es un artículo de acceso abierto distribuido bajo los términos de una licencia de uso y distribución Creative Commons Attribution (CC-by) España 3.0.

* El presente estudio se ha realizado en el marco del Proyecto del Plan Nacional de I+D Entre la venalidad y la corrupción en la Monarquía Hispánica durante el Antiguo Régimen HAR2014-55305, financiado por el Ministerio de Economía y Competitividad. 
Que la venalidad de cargos para servir en Indias alcanzó unas cotas inusitadas durante el período de valimiento del conde-duque de Olivares es algo que conocemos sobradamente merced a estudios generales como los de Tomás y Valiente ${ }^{1}$ y, últimamente, al detallado trabajo de Ángel Sanz Tapia sobre la evolución y cuantificación de las ventas de cargos de hacienda a lo largo de toda la centuria barroca. ${ }^{2}$ Precisamente este último autor ha demostrado que, junto a la gran almoneda de todo tipo de cargos para ejercer en América que tuvo lugar a partir del año 1674, el período de Olivares fue, con diferencia, una de las etapas venales más álgidas de todo el siglo XVII. $\mathrm{Su}$ análisis cuantitativo, tanto del volumen de provisiones por dinero como de las sumas obtenidas por este medio, revela la existencia de una dinámica venal intensa de la que aun restan numerosos aspectos que estudiar para dar respuesta a interrogantes esenciales sobre los procesos enajenatorios en un contexto político en el que las denominadas «urgencias de la guerra» justificaban casi todo. Incluso, que sobre la mesa del Consejo de Indias se planteara la posibilidad de que a ese mercado se pudieran incorporar las magistraturas de justicia, algo que siempre se había considerado como inalienable pues la justicia del rey jamás debía verse «manchada» por semejante proceder. ${ }^{3}$ Habría pues que esperar hasta el año $1683^{4}$ para que las plazas de oidores y alcaldes del crimen de las audiencias americanas entrasen a ser una pieza más de la fabulosa bolsa de dinero que representó para la hacienda de Madrid la provisión de cargos de la administración americana en sus cuatro ámbitos principales: hacienda, gobierno, justicia y guerra. ${ }^{5}$

Sin embargo, de la almoneda de cargos para ejercer en América que tuvo lugar en la corte, y más concretamente en el Consejo de Indias, tenemos hasta hora tan pocos datos como numerosas interrogantes. Desde una perspectiva historiográfica que trata de salir del marco cuantitativo, se trataría de dar respuestas a problemas esenciales como son conocer las razones de esa intensificación de ventas que tuvo lugar durante el valimiento de Olivares, acercarnos a la totalidad del «mercado», explicar cuáles fueron las atribuciones de los agentes del rey encargados de las ventas y, por último, aportar una primera aproximación a la aplicación del dinero recaudado.

\footnotetext{
1 Tomás y Valiente, 1982.

2 Es obligada la referencia también al clásico trabajo de Burkholder y Chandler, 1984. Más recientemente Sanz Tapia (2011) ha ampliado la cronología de las ventas hasta 1632.

3 Consulta del 7 de noviembre de 1640, Archivo General de Indias (AGI), Indiferente General, 2689.

4 Sanz Tapia, 2012.

5 A partir de entonces las ventas alcanzarían a la práctica totalidad de la administración indiana. Bertrand, 2011. Andújar Castillo, 2008. Burgos Lejonagoitia, 2015.
} 
Tras las múltiples referencias de Schäfer, la obra de Parry fue la primera que llamó la atención sobre la existencia de procesos venales en Indias, ${ }^{6}$ pero sin duda fue Tomás Valiente quien planteó las líneas principales que habían de seguir las posteriores investigaciones sobre el tema al señalar la importancia de la patrimonialización de oficios en la estructura políticoadministrativa americana. ${ }^{7}$ Aquellas obras pioneras, abrieron una senda de investigación en la que después han profundizado las obras de Burkholder y Chandler, ${ }^{8}$ Sanz Tapia, ${ }^{9}$ Keneth ${ }^{10}$ y las aportaciones de otros investigadores como Muro Romero y Román. ${ }^{11}$ No obstante, lejos de ser un tema agotado, nuevos datos nos ayudan a entender mejor el complejo proceso de implantación del aparato burocrático en la América hispana.

\section{Las vías de venta: Consejo, Juntas y comisiones}

Aunque se ha afirmado que las ventas de oficios de hacienda durante el período de Olivares no se efectuaron a través del Consejo de Indias sino por medio de juntas especiales, tales como la Junta de Vestir la Casa o la Junta de Coroneles, lo cierto es que la importancia de estas últimas en los procesos venales de esta etapa fue muy exigua en relación con los cargos que se tramitaron, no tanto por el Consejo como por algunos de sus consejeros y, en especial, por el conde de Castrillo, García de Haro Avellaneda, presidente del Consejo de Indias entre noviembre de 1632 y el año 1653. El Consejo de Indias benefició directamente cargos de América, pero el mayor volumen de operaciones y negociaciones se desarrolló por medio de una serie comisarios encargados directamente por el rey -o probablemente por el conde-duque de Olivares- para que procedieran a enajenar toda una serie de «productos», entre los cuales destacaron por su volumen los puestos de contador, tesorero, veedor y factor de las cajas reales de la hacienda americana, así como las plazas de contadores de los Tribunales Mayores de Cuentas, aunque, como veremos, ni fueron los únicos ni los de más alta cotización.

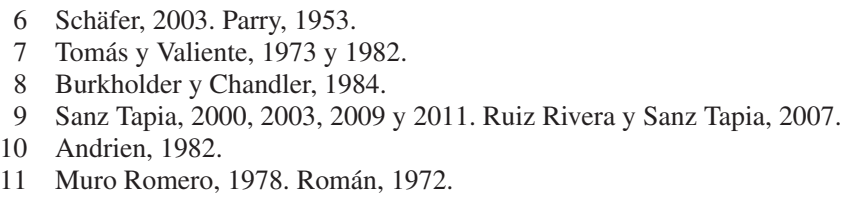


Es más, tanto el Consejo como esos comisionados no solo beneficiaron oficios de Indias sino una serie de «efectos» que venían a configurar todo un conjunto de ingresos extraordinarios que tuvieron como destino la tesorería - receptoría - del Consejo de Indias, aunque en cuentas separadas, una del propio Consejo y las demás con lo beneficiado por cada uno de los comisionados. Por tanto, funcionaron al mismo tiempo varias vías de enajenación de cargos y otros efectos de Indias. De una parte la del Consejo de Indias, de otra la de los distintos comisarios regios con poderes especiales.

Para nutrir las arcas de la tesorería del Consejo de Indias, de las cuales se pagaban desde salarios de los propios ministros y personal del Consejo hasta ayudas de costa pasando por limosnas para obras pías y otra serie de gastos de esta institución, el consejero y presidente de la Casa de Contratación entre 1635 y 1637, Pedro de Vivanco, se ocupó de vender toda clase de efectos y actuó en paralelo a los demás comisionados que enajenaban «productos» similares. ${ }^{12}$ Aparte de los gastos propios del Consejo, de lo que recaudaba se aplicaban algunas cantidades a fines específicos, relacionados tanto con la guerra como con el gasto cortesano. ${ }^{13}$ Las cuentas de lo que corrió por su mano entre 1633 y 1639 son harto elocuentes para analizar la financiación del propio Consejo de Indias: oficios de hacienda de las cajas reales americanas, de los tribunales de cuentas, naturalezas de Indias, licencias de navíos para navegar en la Carrera ${ }^{14}$ cargos de la propia Casa de Contratación, prórrogas de encomiendas, e incluso el importe de algunas multas, caso de la de un oidor que había casado sin licencia real. ${ }^{15}$

A lo largo del período de Olivares hubo, como mínimo, tres comisiones - más la mencionada de Pedro de Vivanco y lo que vendió la Junta de Vestir la Casa - para enajenar cargos de América, si bien dos de ellas las podríamos considerar como menores en relación con la gran empresa que asumió el conde de Castrillo a partir del año 1635. La primera, por orden cronológico, fue la que se encargó a una «Junta particular» formada por los consejeros de Indias, Busto de Bustamante, Lorenzo Ramírez de Prado y

12 Vivanco ya había colaborado junto con el duque de Medina de las Torres para idear nuevos arbitrios con los que obtener fondos para la monarquía. Amadori, 2008.

13 Se puede anotar, como ejemplo, que los 15.000 ducados que pagó en 1635 el capitán Juan de Quesada por una plaza de tesorero de Lima se aplicaron al pago de una partida de dinero que se debía enviar a Liérganes para la artillería y otra parte a las obras del Buen Retiro. AGI, Contaduría, 76.

14 Tales licencias funcionaban, cual lo ha explicado Carmen Sanz Ayán, como coberturas legales para el comercio ilegal. Sanz Ayán, 2015.

15 AGI, Contaduría, 76. 
el duque de Medina de las Torres - yerno del conde-duque de Olivaresentre los años de 1632 y $1633 .{ }^{16}$ Fue una comisión directa dada por el rey para que vendieran empleos de América cuyo producto se debía entregar al receptor - futuro tesorero- del Consejo de Indias, quien luego debía hacer los libramientos siguiendo órdenes del rey. En todo caso, los responsables de negociar con las aspirantes a comprar los cargos, o con sus agentes en Madrid, fueron los mencionados consejeros. De ellos, Lorenzo Ramírez de Prado, tendría un papel decisivo en la posterior Junta de Vestir la Casa, creada, como su nombre indica, para financiar una parte del gasto cortesano y que tuvo en la venta de cargos —incluidos algunos de Indias - su principal fuente de ingresos. ${ }^{17}$ Por esta primera Junta se beneficiaron fundamentalmente empleos de las cajas americanas así como un puesto militar, el de Sargento Mayor de México (que luego no fructificó y se le devolvió el dinero al comprador por la negativa del Consejo a que se vendiese ese oficio) ${ }^{18}$ y dos prórrogas por una vida más cada una para conservar sendas encomiendas para los que por entonces eran sus propietarios. ${ }^{19}$

\section{PRODUCTO DE LOS OFICIOS DE INDIAS ENAJENADOS EN MADRID (NOVIEMBRE 1632-NOVIEMBRE 1638) ${ }^{20}$}

\begin{tabular}{|l|c|c|}
\hline \multicolumn{1}{|c|}{ Comisionados } & Reales & Porcentaje \\
\hline Conde de Castrillo & 3.299 .247 & $73,1 \%$ \\
\hline Junta de consejeros & 841.441 & $18,6 \%$ \\
\hline Juan Pardo Arenillas & 173.147 & $3,8 \%$ \\
\hline Junta de Vestir la Casa & 201.300 & $4,5 \%$ \\
\hline Total & 4.515 .135 & $100 \%$ \\
\hline
\end{tabular}

16 AGI, Contaduría, 64.

17 Ramírez de Prado aportó a la Junta su profundo conocimiento de la legislación y del funcionamiento de la administración de las Indias, que servía para identificar qué oficios eran susceptibles de ser enajenados. También utilizó sus relaciones familiares para favorecer la empresa, siendo su hermano Alonso Ramírez de Prado, oidor en Granada, uno de los principales comisionados por la Junta. Gil Martínez, 2015b, 769.

18 AGI, Indiferente General, 583, lib. 1, $108 \mathrm{r}$.

19 AGI, Contaduría, 64.

20 Fuentes: AGI, Contaduría, 73. Los datos relativos a la Junta de Vestir la Casa han sido extraídos de Archivo General de Simancas (AGS), Consejo y Juntas de Hacienda, 162. No está incluido lo beneficiado por Pedro de Vivanco en la Casa de Contratación. 
Otra comisión se dio al consejero de Indias Juan Pardo Arenillas en los años de 1638 a 1640, pero fue no solo limitada en el tiempo sino en cuanto al número de transacciones - apenas alcanzó la decena de operacionespues no podía, ni debía, competir con el gobernador del Consejo, el todopoderoso conde de Castrillo, quien por entonces gozaba de una comisión amplia y muy especial para enajenar plazas de Indias, con las de hacienda a la cabeza. ${ }^{21}$ No obstante, la explicación de esta comisión se encuentra en que Pardo Arenillas fue encargado de vender efectos desde abril de 1638 para financiar las propinas de los consejeros y el mantenimiento de una compañía de soldados cuyo gasto debía soportar el Consejo de Indias, labor esta última de la cual se ocuparía años después el mismo conde de Castrillo. ${ }^{22}$ Entre los efectos que vendió el más considerable por su valor fue el de Proveedor General de armadas y flotas de Indias de la Casa de Contratación, beneficiado por Alonso Ortega en octubre de 1638 por 12.000 ducados.

El problema durante esos años, al igual que sucedía para los cargos que se enajenaban para servir en Castilla, fue el de la competencia entre los distintos «vendedores» que ofrecían de forma simultánea cargos por doquier, lo cual, sin duda debió incidir en una baja de los precios. ${ }^{23}$ Era conocido el perjuicio que causaba a la Real Hacienda tal concurrencia, pues cualquier comprador podía acudir a cada una de esas oficinas en las que por dinero se despachaban toda suerte de empleos pero, a causa del interés particular de los consejeros en mantener activas e incluso ampliar las comisiones recibidas; y de la creciente necesidad de fondos para la guerra, el mercado venal no hizo sino aumentar aun a costa de provocar caídas en los precios.

Además, estos «espacios de competencia» fueron manejados a la perfección por algunos de los más activos consejeros. Uno de esos «espacios» de que formaban parte miembros del propio Consejo de Indias estuvo en la Junta de Vestir la Casa, de la cual fue miembro Lorenzo Ramírez de Prado, y a la que también llegó a asistir Juan Pardo Arenillas. Además, el propio Lorenzo Ramírez de Prado sería quien proseguiría la comisión de Juan Pardo tras la muerte de este, concentrando en su mano varias de las vías de beneficio del Consejo de Indias. ${ }^{24}$ Durante el tiempo que se mantuvo activa,

21 AGI, Contaduría, 71 y 76.

22 AGI, Contaduría, 76.

23 En el caso castellano se expresaba así Luis Gudiel en el ejercicio de varias comisiones que recibió en el reino de Granada: «Veo destruir el servicio del Rey en que las materias de las gracias y ventas de oficios corran por diferentes manos porque con eso los merchantes acuden siempre a quien le hace mayor barato». Citado en Gil Martínez, 2015c, 222.

24 Consulta del 20 de agosto de 1641, AGI, Indiferente General, 762. 
entre los años 1636 y 1643, negoció algunas operaciones de cargos relacionados con Indias y en especial con el circuito de la plata americana desde su origen hasta la llegada a Sevilla. Sirvan de ejemplo los casos del oficio de fundidor y ensayador mayor de la Casa de la Moneda de México, vendido a los carmelitas descalzos por 6.000 pesos de a 8 reales en $1641,{ }^{25}$ o la contaduría de la Armada de la Guarda de la Carrera de Indias, adquirida a perpetuidad por Antonio Arrieta Mascarúa a cambio de sus servicios previos y del desembolso pecuniario de 12.000 ducados de a 11 reales cada uno. ${ }^{26}$

\section{El conde de Castrillo. Unas notas biográficas}

García de Haro y Avellaneda, conde de Castrillo, ocupó una posición muy destacada en la administración de la monarquía durante el valimiento de Olivares, pues a su alcurnia y parentesco con el conde-duque se añadía una trayectoria como burócrata de carrera que lo hacía ideal para ocupar altos puestos en los Consejos. El retrato que nos pintan de él sus coetáneos es el de un personaje inteligente, trabajador, serio y ambicioso. ${ }^{27}$

Era el segundo hijo del marqués del Carpio, que al no estar destinado a heredar el mayorazgo, comenzó sus estudios de leyes en el Colegio de Cuenca en Salamanca en 1610. Siguiendo el cursus honorum de los colegiales, García de Haro ganó primero una cátedra e incluso llegó a ser elegido rector de su colegio mayor, como lo fuera anteriormente Olivares, antes de entrar en las instituciones de la monarquía. ${ }^{28}$ Allí conoció a muchos de los que posteriormente serían sus compañeros en los Consejos de la monarquía, como el consejero de Indias Juan de Solórzano ${ }^{29}$ o el jurista Juan Bautista de Larrea ${ }^{30}$ entre otros.

En 1619 fue nombrado oidor de la Chancillería de Valladolid donde ejerció casi cuatro años hasta que, coincidiendo con el ascenso al trono de Felipe IV y la renovación en los cargos de gobierno, fue llamado a la corte. La alianza entre la casa de Haro y la de Guzmán, a la que pertenecía el valido de Felipe IV, constituyó el pilar sobre el que construyó una larga y meteórica carrera en la administración.

25 AGS, Consejo y Juntas de Hacienda, 162.

26 Archivo Histórico Nacional (AHN), Estado, 2312.

27 Son las palabras del conde Clarendon, en Elliott, 1998, 702.

28 Mazín, 2012, 85.

29 García Hernán, 2007, 68.

30 Volpini, 1996, 68. 
En 1622, el rey, influido por Olivares, lo eligió para ocupar una plaza en el Consejo de Órdenes entre la terna de oidores propuesta por la Cámara de Castilla. ${ }^{31}$ Poco después de llegar a la corte, el valido, necesitado de hombres de confianza dentro de las instituciones del sistema polisinodial y percibiendo ya la valía de García de Haro, propició su promoción al Consejo de Castilla en 1624 y, al año siguiente, a la Cámara. ${ }^{32}$ Durante un breve periodo de tiempo también ejerció como gobernador interino del Consejo de Indias en 1626, una experiencia que le resultaría valiosa, pues en 1632 asumió la presidencia del mismo y la desempeñó hasta 1653, cuando se ausentó para ocuparse del virreinato de Nápoles. Asimismo, entró a formar parte del Consejo de Estado en 1630 y sirvió durante unos meses en 1642 como gobernador interino del Consejo de Hacienda. ${ }^{33}$

Su casamiento en 1623 con María de Avellaneda le permitió acceder al título de conde de Castrillo y emparentar con Bernardino de Avellaneda, primer titular de la dignidad, el cual había sido presidente de la Casa de Contratación y Asistente de Sevilla, por lo que tenía un profundo conocimiento de las cuestiones relacionadas con las Indias. El último cargo que ocupó el primer conde de Castrillo fue el de virrey de Navarra, destino que supo aprovechar en su favor, pues cuando en 1629 el rey decretó que los consejeros de Castilla saliesen a pedir el donativo por los territorios castellanos García de Haro fue enviado precisamente a Navarra. Dicho donativo, conocido como de «las guerras de Italia», fue uno de los primeros ensayos del reinado en los que se empleó la venalidad de forma sistemática para obtener financiación extraordinaria. Castrillo demostró entonces una enorme pericia en su comisión pues no solo recaudó una cantidad considerable de dinero sin generar grandes conflictos, sino que innovó reduciendo los costes de recaudación para la Real Hacienda. Para ello negoció directamente con Octavio Centurión, marqués de Monesterio, asentista encargado del asiento y abastecimiento de los presidios en los que se incluían los de Navarra, ${ }^{34}$ que los pagadores de estos recibiesen el dinero de los plazos que se obligaban a pagar la población a cambio de las mercedes. ${ }^{35}$ Posteriormente

31 Gómez Rivero, 2003, 728.

32 Fayard, 1982.

33 La lista de cargos que ocupó Castrillo a lo largo de su carrera resulta asombrosa pues a lo ya expuesto hay que sumarle las presidencias de los Consejos de Italia y Castilla en la segunda mitad del siglo. También fue uno de los elegidos por Felipe IV para formar la Junta de Gobierno que debía ayudar a Mariana de Austria a asumir la regencia tras su muerte.

34 Sanz Ayán, 2011, 865.

35 AGI, Contaduría, 88, ramos 2-5. 
el conde-duque de Olivares tuvo en cuenta los buenos resultados obtenidos por su pariente cuando la monarquía hispánica entró en la Guerra de los Treinta Años, y con ella en una campaña venal de proporciones desconocidas hasta entonces.

Otro elemento fundamental para explicar las múltiples comisiones que recibió Castrillo para enajenar mercedes así como el amplísimo margen de libertad del que gozó es la relación que mantuvo con el soberano y su entorno. Desde su llegada a la corte, Olivares lo introdujo no solo en los entresijos del aparato administrativo sino también en el epicentro del poder, la Casa Real. Para mantener su influencia sobre el monarca el valido creó a su alrededor un círculo de aliados que le permitían controlar las vías de acceso al rey. Como parte de esta estrategia Castrillo fue nombrado gentilhombre de cámara de Felipe IV, lo que le permitió entrar en contacto directo con el monarca y establecer con él una relación de confianza que extendería luego con la reina, de modo que logró ir asentando sus propias bases de poder al margen del conde-duque, ${ }^{36}$ de forma que en 1640 sería nombrado mayordomo mayor de la Casa Real de Castilla. ${ }^{37}$ Castrillo fue progresivamente distanciándose de Olivares hasta el punto de que llegó a conspirar para provocar su caída en 1643.

Los conocimientos de leyes, la habilidad mostrada en la recaudación del donativo y la confianza que mostraron en él monarca y valido, le convirtieron en la elección idónea para estar al frente de la gran almoneda de oficios de Indias. Además, debido a su refinado gusto artístico, en varias ocasiones se le confió no solo la provisión de fondos para los palacios reales sino también su decoración, ${ }^{38}$ lo que ayudó a estrechar los lazos con los monarcas. Del tamaño de la almoneda que efectuó directamente da una idea la cifra que, según la relación de sus cargos y servicios, llegó a aportar a lo largo de todos sus años de servicio a las arcas regias 31 millones de escudos, ${ }^{39}$ cantidad desorbitada si tenemos en cuenta que superaba con creces los ingresos anuales que percibía la monarquía de sus rentas. ${ }^{40}$ Además

36 Debido a este afecto Castrillo fue el encargado de organizar el funeral de la reina.

37 Elliott, 1998, 702.

38 Gil Martínez, 2015a.

39 Relación de los títulos, puestos y servicios de don García de Avellaneda y Haro, conde de Castrillo, Google Books. Se trata de un documento procedente de la Biblioteca Nacional de Austria (31. Aa. 47), en el que se hace un extenso relato de su carrera; al final hay una certificación de la gruesa cantidad beneficiada por Castrillo, dada por el contador del Consejo de Indias Francisco Antonio Mancolo.

40 Andrés Ucendo y Lanza García $(2008,161)$ citan tanteos que rondan los 15 millones de ducados anuales durante el reinado. 
de las comisiones que recibió, Castrillo también participó en numerosas Juntas, siendo uno de los principales ministros especializados en la recaudación de fondos de forma extraordinaria tanto en los territorios americanos como en la península.

\section{La almoneda del conde de Castrillo, 1632-1639}

La primera comisión para enajenar cargos, en su calidad de gobernador del Consejo de Indias, pero siempre a título personal, se la dio Felipe IV el 16 de octubre de 1635, es decir, cinco meses después de que Francia declarara la guerra a España. Tal comisión venía a ampliar otra previa para proveer parte del crédito que se debía a los asentistas que habían hecho préstamos a la monarquía. Por la misma se le daban facultades para «poder beneficiar efectos, rentas de oficios en las Indias de lo que en esta mi corte y estos reinos se proponen y ofrecen», de manera que de todo lo que proveyese recibiese después el correspondiente despacho del Consejo de Indias. Además, dicha comisión, a pesar de las urgencias de numerario para la guerra, precisaba de forma clara el destino del dinero: que todo lo que «conde de Castrillo beneficiare se convierta para pagar lo que se ha gastado y gastare en el Buen Retiro y en la casa de la Zarzuela y en las demás cosas que le tengo y mandare y que el receptor de mi Consejo de Indias reciba por ordenes del dicho conde de Castrillo lo que resultare de los dichos efectos y lo pague también por órdenes y libranzas suyas». ${ }^{41}$

Sin embargo, apenas transcurridos tres meses de esa comisión, Castrillo vio nuevamente ampliados sus poderes para el mismo fin, probablemente facultándole para enajenaciones de cargos que no estaban incluidos en aquella primera comisión. Pero la razón de esa ampliación no estuvo solo en las necesidades de la guerra sino también en otras causas más oscuras. Lo cierto es que los «efectos de Indias», y dentro de ellos la venta de oficios, se presentaron como una fuente de dinero rápida, en efectivo, buena parte de ella en moneda de plata, que podían permitir aprontar caudales en tiempos de extrema necesidad.

La ampliación del «mercado» de Castrillo tuvo su fundamento, por un lado, en los deseos del monarca de recaudar más, y por otro en la amplia experiencia del conde en tales menesteres. El 27 de diciembre remitió el

41 AGI, Contaduría, 73. 
rey a Castrillo un decreto para que se estudiase en el Consejo de Indias un memorial de expedientes que había mandado beneficiar para que el dinero procedente de ellos se entregase al Protonotario de Aragón, Jerónimo de Villanueva, «para cierto gasto secreto de mi servicio de que no se le había de hacer cargo ni pedir cuenta». ${ }^{42}$ El Consejo de Indias, estudió el memorial pero encontró «algunos inconvenientes» que impedían que todos los medios propuestos en el mismo se pusiesen en ejecución, es decir, que debía contener tal vez cargos de justicia. Castrillo que ya gozaba de su comisión previa para enajenar, hizo una consulta particular al monarca por la cual se ofrecía a recaudar el mismo dinero pero obteniéndolo de «otros efectos» sobre los que el Consejo de Indias no pudiese plantear objeción alguna. El rey aprobó su propuesta y le encargó que se ocupase de ese negocio «y procurare suplir las dichas cantidades con anticipación de plazos y beneficiar los dichos expedientes y ajustar con el Protonotario de Aragón el asiento que sobre ellos estaba contratado para el efecto secreto de mi servicio». En ejecución de esa orden, el conde de Castrillo no solo benefició las cantidades de los dichos expedientes sino que, a instancia del dicho Protonotario de Aragón, y en nombre del rey, firmó una cédula de 23.429 ducados de a 11 reales de plata que se deberían pagar al financiero genovés Carlos Strata por el asiento que con él había tomado el dicho Protonotario de Aragón. ${ }^{43}$ Así pues, lo que hizo Castrillo fue suplir el dinero que se debía pagar a Strata y vender los efectos que contenía el memorial remitido por el rey al Consejo de Indias, si bien lo hizo con «productos» que no estuviesen reprobados expresamente por dicho órgano. ${ }^{44}$

Castrillo recibió poderes omnímodos del rey para negociar personalmente con aspirantes o agentes de negocios los contratos, asientos o «conciertos» que iban a permitir a numerosos individuos colocarse en las cajas americanas merced a simples servicios pecuniarios, contaran o no con servicios previos a la monarquía. Es más, recibió facultades especiales muy superiores a las que se iban a dar a los mencionados consejeros. Era el encargado de pactar el precio, las condiciones de uso del cargo, las calidades y preeminencias y, desde luego, los plazos de pago. De cada ingreso, de cada «negocio» que corriera por las manos de Castrillo se debía entregar el

42 AGI, Contaduría, 76.

43 Ibidem

44 Además del pago al financiero Carlos Strata, la cuenta final que presentó el conde de Castrillo contenía otros pagos, entre ellos una cantidad para abonar parte de la merced de 4.000 ducados que en octubre de 1634 había concedido Felipe IV al sobrino del conde, don Luis de Haro. 
dinero en una cuenta aparte para los efectos que el rey ordenare librarlos. En suma, quien concedía la «gracia» para ejercer un cargo en América no era el rey sino Castrillo. Lo deja muy claro un asiento de la contaduría de mayo de 1644 en el que con motivo del ingreso de Juan de Saiceta de 24.000 reales por la plaza de tesorero de las minas de Oruro, el contador del Consejo de Indias anotó sin ambages que «le concedió la dicha gracia el conde de Castrillo» ${ }^{45}$ Castrillo actuaba pues siguiendo las amplias facultades concedidas por el monarca para «componer negocios de Indias», «beneficiar efectos», o «negociar expedientes». Lo que resulta más complejo de dilucidar es si siempre actuó solo o se valió de algunas personas de su confianza. Sabemos que en Sevilla, siguiendo órdenes de Castrillo, negoció efectos de Indias el conde de Peñaflor, presidente de la Casa de Contratación, quien no solo recaudó dinero de «beneficios» sino que también hizo pagos con cargo al mismo, siempre previa orden del conde de Castrillo. ${ }^{46}$ Igualmente es más que probable que de las operaciones de alto valor se ocupara personalmente Castrillo, en tanto que de las de poca monta lo hicieran algunos servidores suyos.

Su poder fue tal en estos «negocios» — como la propia documentación los definía - que podía incluso anular de forma unilateral pactos ya firmados. Así, por ejemplo, en enero de 1638 vendió una plaza de tesorero de Acapulco a un tal Sebastián Caja por un importe total de 41.000 reales, pagaderos a plazos, pero la operación la abortó un tiempo después el propio Castrillo «por haber beneficiado este oficio con otra persona que dio más por él». ${ }^{47}$

Pero tan interesante como esas facultades fue el hecho de que el mismo Castrillo se encargase personalmente de la distribución — siguiendo órdenes del rey, según la documentación- del dinero que recaudaba de las ventas de cargos. De cada contrato, o asiento, el dinero se ingresaba en la receptoría del Consejo de Indias en una cuenta separada de la cual no podía salir un solo maravedí si no era precediendo orden expresa del conde y comunicación a través del secretario de dicho Consejo.

Castrillo gozaba de este modo de un extraordinario poder personal, pues de sus asuntos relativos a la venta de cargos no debía dar cuenta alguna al Consejo de Indias. Su actuación se desarrolló siempre en nombre de un monarca que le había dotado de poderes excepcionales que le permitían

45 AGI, Contaduría, 91.

46 AGI, Contaduría, 64.

47 AGI, Contaduría, 73 y 76. 
fijar las condiciones contractuales con agentes de negocios y compradores. No en vano, entre esas condiciones, una de las más importantes para el pago de los segundos plazos del precio de los oficios adquiridos - que casi siempre se solía hacer en Indias - era que los adquirientes se comprometían a efectuarlo con el rey, no con Castrillo. Por tanto, las «escrituras de obligación» que se formalizaban ante escribano tras cerrar los contratos se hacían entre los deudores de esos segundos plazos y el monarca. Como modelo podemos reseñar el caso de la escritura de obligación firmada 11 de julio de 1642 por el agente de negocios Gregorio de Vega —uno de los más activos en este período-, por la que en nombre de Antonio de Medina Sánchez de Cuellar, vecino de Sevilla, se obligaba a pagar al rey en un plazo de cuatro meses, y en su nombre al receptor del Consejo de Indias, 1.500 pesos de a ocho reales por la futura de una de las cuatro plazas de contador de cuentas de la avería de la Casa de Contratación, tras haberlo negociado todo con el conde de Castrillo, quien tenía «poder especial para beneficiar expedientes de Indias». ${ }^{48}$

El procedimiento que seguía cualquier operación de venta consistía en la presentación de una oferta ante el conde de Castrillo por parte de quienes aspiraban a hacerse con un cargo, bien personalmente, bien a través de agentes de negocios. Dicha oferta, que solía contener el precio que estaban dispuestos a pagar, los plazos de entrega del dinero, e incluso la moneda - pues no era lo mismo pagar en vellón que en plata—, era regulada por el propio Castrillo, es decir, determinaba si aceptaba las condiciones o las modificaba. A partir de ese momento se abría una negociación en la que por parte de la Corona todo el poder decisorio radicaba en Castrillo, quien además tenía poder para determinar en qué cuenta se ingresaba el dinero $\mathrm{y}$, seguramente siguiendo órdenes superiores, a qué se aplicaba el dinero obtenido.

El mercado no pareció tener demasiados límites pues mediante el sistema de futuras se podía enajenar varias veces un mismo oficio sin que estuviese vacante. Precisamente, la existencia de estas futuras, más allá de la necesidad de conocer con detalle los puestos de la administración indiana, debió estar detrás de los trabajos que algunos oficiales del Consejo emprendieron en la década de 1640 con el fin de trazar un exhaustivo panorama del sistema de gobierno en América y, sobre todo, precisar qué puestos eran de provisión de virreyes y gobernadores y cuáles correspondían a la

48 Archivo Histórico de Protocolos de Madrid, Prot. 5777, 324r-325v. 
provisión del monarca. Las relaciones de oficios como las elaboradas a mediados de la centuria por Juan Díez de la Calle se enmarcarían, como han señalado Jean Pierre Berthe y Thomas Calvo, en la necesidad de la Corona de conocer con detalle todos los hilos de la administración imperial, de saber «quantos oficios y ministerios hordinarios y extraordinarios de todas profesiones se proveen» en todos sus dominios, ${ }^{49}$ pero también habría que ubicarlas en ese contexto de voracidad fiscal de una monarquía que halló en el mercado americano uno de los más sustanciosos graneros de caudales.

Si bien el beneficio de cargos de la hacienda indiana fue el que más número de transacciones registró - y en conjunto, el que generó un mayor volumen de ingresos- durante los años que Castrillo estuvo comisionado para la venta de empleos de Indias, algunas operaciones singulares reportaron sustanciosas sumas que, en algún caso, llegaron a superar al total de ingresos procedentes de la enajenación de cargos de hacienda. Así, mientras que en el año 1639 el beneficio de puestos de hacienda proporcionó a las arcas de la tesorería del Consejo de Indias 40.000 pesos,${ }^{50}$ una operación realizada ese mismo año por el conde de Castrillo con un agente de negocios, Bernabé de Robles, la compra por parte de la ciudad de Cartagena de Indias de los oficios de corredor general y fiel ejecutor, con carácter de perpetuos, se pactó en un precio de 100.000 pesos de a ocho reales. ${ }^{51} \mathrm{Y}$ es que las perpetuaciones de oficios fueron, con diferencia, las principales operaciones venales que tuvieron lugar durante el valimiento de Olivares y durante todo el siglo XVII. Es el caso de la perpetuación del cargo de escribano mayor de la Mar del Sur que consiguió en 1636 Ana de la Cueva por un servicio de 24.000 ducados, con el fin de que el cargo que había desempeñado su marido, Francisco de la Presa, quedara para siempre de su propiedad y por tanto pudiera transmitirlo a sus hijos o venderlo a un tercero. ${ }^{52}$

De entre las perpetuaciones, las que mayor volumen de ingresos generaron a la particular cuenta de Castrillo en el Consejo de Indias fueron las de una serie de cargos enajenados en la Casa de Contratación de Sevilla, institución que durante el siglo XVII experimentó la venta de casi la totalidad de sus cargos, ora fuesen como beneficios vitalicios ora como ventas a perpetuidad, un proceso que, como se ha afirmado, permitió que

49 Berthe y Calvo, 2011, 68.

50 Sanz Tapia, 2011, 164.

51 AGI, Contaduría, 81.

52 AGI, Contaduría, 76. La negociación se había realizado entre el conde de Castrillo y el jesuita Francisco Crespo, quien había recibido poder de la citada Ana de la Cueva. 
comerciantes y hombres del Consulado accedieran a los puestos de la Casa de Contratación. ${ }^{53}$

El conde de Castrillo, encargado por Felipe IV de beneficiar «expedientes de Indias», se ocupó personalmente de negociar y tratar las ventas a perpetuidad de los principales puestos de la Casa, es decir, empleos que no eran para ejercer en América pero que entraban dentro del ámbito competencial del Consejo de Indias. Sin duda, debieron ser complejas operaciones pues fueron muy elevadas las sumas de dinero en juego y no había precedentes algunos de transacciones similares.

La primera perpetuación de alto valor que se produjo en la Casa de Contratación fue la compra en 1634 por parte de Diego Villegas, por la suma de 50.000 ducados, del puesto de contador mayor. ${ }^{54}$ En realidad con esta venta lo que se hizo fue privatizar uno de los tres puestos fundamentales de la sala de gobierno de la Casa, pues el título que adquirió fue el «contador mayor juez oficial» de la Casa, de modo que quedaban a provisión del rey los otros dos cargos, los de juez oficial tesorero y el de juez oficial factor. Según Schäfer, este «negocio» no había sido competencia de Castrillo sino del camarista de Castilla José González de Uzqueta y se habría producido en 1632, si bien la operación debió cerrarse en julio de 1634, fecha en que Villegas abonó la citada cantidad. ${ }^{55}$

En 1637 otro oficio que debía velar por el control de los productos del comercio con Indias, el de veedor general de las armadas y flotas de la Carrera de Indias fue vendido por Castrillo en 12.000 ducados a Alonso Tapia Vargas. ${ }^{56}$ En 1642 Castrillo volvería a negociar los precios y condiciones de nuevos oficios perpetuados en la Casa de Contratación, entre los cuales el de mayor valor fue el de alguacil mayor de las armadas y flotas de Indias, adquirido por Pedro de la Mata Velasco en 10.000 ducados. ${ }^{57}$

53 Andújar Castillo, 2014, 49.

54 Ibidem, 54. Esta compra tuvo dos fases, la primera, de 50.000 ducados, por la que adquiría el cargo y otra segunda en 1641 por la que ampliaba las facultades de goce del mismo al abonar 5.000 ducados más a cambio de que se le concedieran nuevas facultades, entre ellas la de nombrar teniente que lo sirviera. AGI, Contaduría, 88.

55 Schäfer, 2003, t. I, 312. Además de los 50.000 ducados, Villegas tuvo que presentar fianzas por importe de otros 30.000 ducados, para cuyo abono tuvo que hipotecar el oficio recién adquirido. AGI, Contaduría, 402.

56 En diciembre de 1639, junto con Antonio Mascarúa, que había adquirido también como perpetuo a través de la Junta de Vestir la Casa en 1637 el puesto de Contador de la Armada de la Guarda de la Carrera de Indias, pagó una cantidad adicional a cambio de que se le concedieran diversas facultades, entre ellas la de «servir sus oficios en sus casas». AGI, Contaduría, 71.

57 Estas cifras ya fueron aportadas hace tiempo por Domínguez Ortiz, 1959, 117-134. 
El único empleo de Indias que vendió como perpetuo desde Madrid el conde de Castrillo fue el de tallador mayor de la Casa de Moneda de Potosí, adquirido por 8.750 ducados de a 11 reales por el Colegio de la Compañía de Jesús de Villafranca del Bierzo, representado para tal inversión por fray Antonio de Velázquez. ${ }^{58} \mathrm{El}$ «asiento», como es obvio, comportaba el ejercicio del cargo por medio de teniente o, lo que es lo mismo, que los frailes leoneses lo pudiesen arrendar a quien pretendiere desempeñarlo personalmente. La explicación a esa transacción hay que buscarla en que el titular del oficio, que lo poseía con carácter de renunciable, Gabriel de Robles, oriundo de Villafranca del Bierzo, había legado sus bienes, y entre ellos el mencionado oficio, para que se aplicaran a la fundación del Colegio. ${ }^{59}$ Una vez que el oficio estuvo en poder de los jesuitas procedieron a transformarlo en propiedad perpetua mediante ese nuevo servicio pecuniario que negociaron con el conde de Castrillo.

Al margen de los oficios, el conde de Castrillo vendió otra serie de expedientes de menor monto económico pero no por ello menos relevantes. Entre ellos destacan las concesiones de «naturalezas de Indias», es decir naturalizaciones de extranjeros para tratar y comerciar con América, por módicas cuantías, al estar tasadas en 400 ducados aunque alguno llegó a pagar hasta 500 ducados.$^{60}$ Del tema se ha ocupado con gran solvencia José Manuel Díaz Blanco, quien además ha demostrado cómo los intereses de los comerciantes nacionales, la oposición del Consulado y del Consejo de Indias a la concesión de estas naturalizaciones por dinero, provocaron que años después acabaran siendo revocadas por el rey y devuelto el dinero a quienes las habían adquirido. ${ }^{61}$ El mismo Díaz Blanco ha señalado que el propio conde de Castrillo fue contrario a la venta de las naturalezas de Indias y que denunció las funestas consecuencias que tal procedimiento tenía para el comercio, ${ }^{62}$ pero sin embargo las vendió personalmente, al menos entre septiembre de 1640 y noviembre de $1642 .{ }^{63}$

La Carrera de Indias tuvo su segundo ámbito venal en las ventas en pública almoneda de los maestrajes de plata, cargos que se comenzaron a enajenar a finales de 1636 por parte de la Junta de Vestir la Casa, a propuesta

58 AGI, Contaduría, 76.

59 Campos Sánchez-Bordona, 1994, 60-80.

60 AGI, Contaduría, 86.

61 Díaz Blanco, 2011, 314-328; 2008, 321-336.

62 Díaz Blanco, 2008, 323.

63 AGI, Contaduría, 86. Durante ese período, según las cuentas del propio Consejo, el conde de Castrillo vendió, al precio de 400 ducados cada una, diez naturalezas para tratar y comerciar con Indias. 
de la propia Junta. Se trataba de puestos fundamentales en la Carrera pues se encargaban del registro de todos los metales preciosos, tanto los de la Real Hacienda como los de particulares, que se enviaban desde los puertos americanos hasta la Casa de Contratación de Sevilla. ${ }^{64}$ Los nombramientos para maestres de plata los dieron en primera instancia los generales de las flotas, luego, desde 1598, la Casa de Contratación, aunque contando con el parecer del Consulado. A raíz de la quiebra de uno de ellos, el conocido Domingo de Ipeñarrieta, ${ }^{65}$ pasaron en 1615 a ser nombrados por el Consejo de Indias, previa propuesta por la Casa de Contratación y del Consulado.

Que puestos tan importantes entraran a formar parte de subastas públicas no se justificaba por las urgencias de la guerra sino por el interés particular del conde-duque de Olivares en asegurarse la percepción de una renta de 12.000 ducados anuales que el rey le concedió en septiembre de 1638 y que inicialmente le fueron situados en las encomiendas de indios que estuviesen vacas en Perú, «prefiriendo en la situación a cualesquier otras personas que tuviesen semejantes mercedes aunque fuesen anteriores a la suya». Sin embargo, dadas las dificultades y retraso en el cobro de esa cantidad por parte de Olivares, el rey ordenó en diciembre de 1639 que en lo sucesivo se le situase dicha renta de lo que «se beneficiaren los maestrajes de plata de la Capitana y Almiranta de los galeones de mi Armada Real de la Guarda de Indias, Capitana y Almiranta de las flotas, o de otros cuatro navíos que él eligiere en cada navegación» ${ }^{66}$

Desde luego el conde-duque, seguramente bien informado a través de Castrillo, conocía la realidad de la cotización de las almonedas de esos puestos de maestres de plata. Como mostró en su día Carlos Álvarez Nogal, la capitana y almiranta eran los navíos con mayor volumen de registro y las que mayores beneficios podían producir a los maestres de plata ${ }^{67}$ Es por ello que fueron los que mayor cotización alcanzaron en las subastas y los que fueron patrimonializados por activos mercaderes u hombres a su servicio, pues podían concurrir a las sucesivas pujas que año tras año venían a privatizar tan decisivo cargo para la custodia del tesoro.

Para asegurar aun más el cobro de la crecida renta que le había concedido el rey, la comisión por la cual los maestrajes de plata eran beneficiados por la Junta de Vestir la Casa fue revocada y pasó a ocuparse de ellos

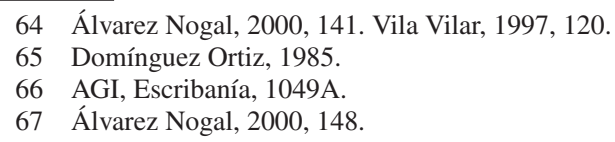


el propio conde de Castrillo. Dado que los potenciales compradores eran siempre mercaderes sevillanos, Castrillo delegó la comisión en Francisco de Mansilla, juez letrado de la Casa de Contratación. ${ }^{68}$

La competencia entre los mercaderes por acceder a los maestrajes, bien directamente bien a través de testaferros, se convirtió en una cuestión pública, posibilitando que durante el tiempo que Mansilla se ocupó de la comisión —desde 1639 hasta su muerte en 1649- para beneficiar los maestrajes de plata, el valor en las subastas de los puestos de las Capitanas y Almirantas fuera subiendo de cotización.

Por último, en el marco de las amplias facultades concedidas a Castrillo para negociar todo tipo de «efectos de Indias», trató asuntos ajenos a la venta de oficios aunque en cuantías inferiores. Así, percibió dinero de «composiciones» pecuniarias por delitos cometidos en América — causa contra Francisco de Arana, vecino de La Habana-, o lo que es lo mismo, el producto de perdones a cambio de dinero como el concedido en diciembre de 1635 a Simón Ribero por importe de 4.000 ducados por el que quedó libre de dos causas que tenía en el Consejo de Indias por dos arribadas de esclavos negros que había hecho en Indias y por las cuales había sido condenado. ${ }^{69}$ Del mismo modo, Castrillo formalizó contratos o asientos para la concesión de prórrogas de disfrute de encomiendas en América. Puede anotarse como ejemplo, el acuerdo que firmó con un agente de negocios de Madrid en marzo de 1638 para que Bartolomé de Mazmela, que gozaba de una encomienda en Nueva Granada —en Santa Fe—, pudiera gozarla por otra vida más, esto es, pasarla o subrogarla en un hijo u otro familiar, a cambio de un servicio de 4.000 ducados que el comprador pagaría en varios plazos..$^{70}$

Como señalamos, la provisión de plazas de justicia por «servicios pecuniarios» estuvo en varias ocasiones en el debate de los consejeros de Indias. Los reparos en «vender la justicia», aunque fuese por medio del sistema del «beneficio», que no comportaba la propiedad del cargo, impidieron que las primeras tentativas de conseguir plazas de oidores de América por este medio tuviesen éxito. Así, aunque Arrigo Amadori en su tesis sobre el gobierno de América durante el período de Olivares afirmó que en abril de 1637, a través de la Junta de Vestir la Casa, Juan Padilla se hizo con una plaza de oidor de Lima a cambio de 14.000 ducados, ${ }^{71}$ lo cierto es que

68 AGI, Contaduría, 403.

69 AGI, Contaduría, 76.

70 AGI, Contaduría, 64

71 Amadori, 2011, 172. 
la operación resultó mucho más compleja. Padilla ya había sido nombrado oidor de la Audiencia de Santa Fe, cargo del que fue depuesto en 1632 por la visita de Antonio Rodríguez de San Isidro Manrique. ${ }^{72}$ Fue condenado a cinco años sin ejercer de oidor, tiempo que aprovechó para viajar a la corte y tratar allí de obtener las dispensas necesarias para ejercer una plaza de oidor en Lima. El principal debate estribaba en que tanto el oidor como su mujer eran naturales de Lima, lo que suponía una doble ilegalidad. La Junta de Vestir la Casa inició el trámite de venta pero se paralizó y se formó una Junta de la que participaron los miembros de las dos instituciones para dirimir la cuestión. ${ }^{73}$ Finalmente Padilla consiguió una plaza de fiscal de Lima ${ }^{74}$ pero la única merced que compró fue la licencia para poder ejercer en su ciudad natal, no el cargo de oidor que por derecho le correspondía.

Sí parece ser que se llegó a «beneficiar la justicia» cuando, dos años después, un tesorero de rentas de Córdoba, Alonso Gutiérrez Torreblanca, ofertó al Consejo de Indias servir con mil vestidos de munición a cambio de que su hermano Melchor fuese designado para una de las audiencias de España o de Nápoles, si bien la consulta fue elevada al rey a través del Consejo de Indias. ${ }^{75}$ Aunque desconocemos el proceso de debate previo a la provisión, el resultado fue que Melchor acabó como oidor de México. ${ }^{76}$ No obstante, dada la fuerte oposición del Consejo a las ventas de oficios de justicia y la inexistencia de casos similares con los que comparar, resulta probable que el candidato tuviese méritos suficientes para obtener la plaza por la vía ordinaria y la oferta venal no fuese más que una forma de adelantar el nombramiento.

En suma, Castrillo, desde su llegada a la presidencia del Consejo de Indias en noviembre de 1632 fue el principal protagonista de la recaudación extraordinaria que se desarrolló para obtener dinero de «beneficios de Indias». Pero no fue esa su única ocupación, pues paralelamente desde su covachuela madrileña enajenó toda clase de bienes del patrimonio regio, desde oficios a exenciones de jurisdicción, pasando incluso por la venta de algún que otro señorío. ${ }^{77}$ Fue sin duda el personaje central de la venalidad en tiempos del conde-duque de Olivares.

72 AGI, Escribanía, 829A.

73 AGS, Consejo y Juntas de Hacienda, 1770.

74 AGI, Contratación, 5421, N.52.

75 Amadori, 2011, 189.

76 AGI, Indiferente General, 454, 181r-182v.

77 AGI, Contaduría, 88. 


\section{El inicio de la década de los 40 . La guerra $y$ el incremento de la venalidad}

La apertura de dos nuevas contiendas en Portugal y Cataluña en el año de 1640 provocó un repunte de las ventas de oficios de Indias. De hecho, el Consejo de Indias se ocupó de financiar la leva y sostenimiento de varias compañías de caballería e infantería que se «levantaron por mano del conde de Castrillo», cuyo coste se hizo recaer sobre la venta de toda clase de efectos del patrimonio real. ${ }^{78}$ Como hemos visto, fue el momento en que se comenzaron a proveer por dinero los puestos de maestres de plata. La venalidad se consolidó como una renta segura, de valor no constante, pues dependió, por un lado de la demanda de compradores y, de otro, de disponer de información precisa para seguir expandiendo ese potencial mercado, ora arrebatando la capacidad de nombramiento a virreyes y gobernadores, ora incrementando el número de nombramientos en régimen de futuras.

Lo cierto es que a partir de 1640, entre los ingresos de dinero por «expedientes beneficiados» por Castrillo encontramos lo que podríamos denominar como nuevos «nichos de mercado». El origen debió estar en esa comisión especial que recibió para financiar la leva de nuevas compañías de caballería. Un somero repaso a esas cuentas evidencia que se mantuvo el beneficio de cargos de la hacienda americana ${ }^{79}$ y que se intensificó la venalidad de oficios de la Casa de Contratación — muchos de ellos enajenados a perpetuidad-, las naturalezas de Indias, algunos oficios subalternos de los tribunales de justicia e incluso que se «criaron» — crearon— nuevos cargos que se proveyeron de inmediato a cambio de dinero.

Amén del inicio de las ventas de los maestrajes, se mantuvo la incorporación a las cuentas de la tesorería del Consejo de Indias de los ingresos procedentes de ventas de toda clase de bienes del patrimonio regio sitos en Castilla —incluidos los oficios - y el producto de algunos «expedientes especiales» relacionados con la guerra.

Comenzando por estos últimos, sorprende encontrar entre las cuentas de Indias dinero que debía haberse ingresado en otras tesorerías. Por entonces, una Junta de Hábitos se encargaba de conceder las mercedes de las órdenes militares castellanas a cambio de servicios pecuniarios, tal y como lo

78 AGI, Contaduría, 87.

79 En el caso de los cargos de hacienda de las cajas americanas, el año de 1640 marcó el máximo de provisiones venales. Sanz Tapia, 2011, 154. 
ha puesto de relieve Agustín Jiménez Moreno. ${ }^{80}$ Pues bien, en las cuentas de Castrillo, exactamente el 6 de septiembre de 1642, se contabilizó un ingreso de 11.000 reales de vellón que en virtud de orden del conde de Castrillo se habían entregado en la tesorería del Consejo de Indias «de lo procedido de dos hábitos». ${ }^{81}$ Poco importaba en aquellos tiempos de extrema necesidad que el rey pudiera incurrir en el delito de simonía. ${ }^{82}$ Relacionados con la guerra también se contabilizaron entre los ingresos de Castrillo una serie de entradas aplicadas para «el apresto de soldados montados» que, con toda certeza, debieron ser las contribuciones que hicieron muchos hidalgos a cambio de no ir a servir a la guerra, esto es, pagar una cantidad para que con su producto se pagase un sustituto.

El segundo bloque de ingresos extraordinarios que se contabilizaron dentro de la tesorería del Consejo de Indias, en la cuenta separada de «beneficios», lo conformaron las ventas de «efectos» del patrimonio regio ajenas por completo a Indias. Esa tarea la desarrolló Castrillo al mismo tiempo que el presidente del Consejo de Hacienda, Antonio Camporredondo, quien realizó su tarea limitándose estrictamente el ámbito castellano, en tanto que Castrillo tuvo sus miras puestas en la distante América. ${ }^{83}$

\section{El conde de Castrillo ¿entre la venalidad y la corrupción?}

La documentación conservada sobre la empresa venal del conde de Castrillo es escueta y apenas aporta otra información que no sea el nombre del comprador, el cargo enajenado y el precio. Excepcionalmente pueden encontrarse las condiciones contractuales de los contratos, prolijas y precisas sobre todo cuando se trataba de perpetuaciones de alto valor.$^{84}$ Negociaciones que tenían lugar en el ámbito de lo privado y, generalmente resueltas «a boca», que no han dejado más huellas documentales que las referidas. Pero es posible interrogarnos acerca de una problemática clave para entender la realidad de estos procesos y, sobre todo, para poner en cuestión las cifras - precios - que manejamos acerca de las transacciones. La pregunta es muy simple ¿El dinero entregado en la tesorería del Consejo de Indias

80 Jiménez Moreno, 2009 y 2011.

81 AGI, Contaduría, 87.

82 Giménez Carrillo, 2011.

83 Los contratos de Camporredondo, en especial los relativos a exenciones de jurisdicción, se pueden encontrar en AHPM, Prot. 5777.

84 Andújar Castillo, 2011. 
coincidió siempre con la suma realmente abonada por los compradores? Dicho de otro modo, ¿en qué medida el conde de Castrillo se pudo lucrar en estas operaciones al pactar con los compradores o sus agentes un precio oficial y otro real? Como es obvio, tales interrogantes son susceptibles de ser trasladadas a otros comisarios regios que a lo largo del siglo XVII fueron encargados para la enajenación de bienes del patrimonio regio, y entre ellos los oficios perpetuos.

Las preguntas antedichas plantean el problema de la corrupción que pudo haber en estas empresas venales que tantos caudales movían. Por lo que respecta al conde de Castrillo, según Janine Fayard, tras dejar la presidencia del Consejo de Indias fue acusado de haber aprovechado el ejercicio de sus cargos en la administración para vender oficios en América que le habrían permitido acumular unos beneficios de 26.000 ducados anuales. ${ }^{85}$ ¿Qué había de cierto en aquella acusación? Aunque sin poder precisar el precio de la «mordida» que Castrillo pudo obtener anualmente de sus negocios en la venta de oficios de Indias, un elemento indiciario abona la tesis aportada por Fayard de que se debió mover en prácticas que hoy calificaríamos como corruptas. Se trata de la certeza de que vendió oficios a precios inferiores de su valor de mercado o, en otros términos, el importe que se ingresó en tesorería no se debió corresponder con el total del dinero pagado por determinados cargos. En mayo de 1637 vendió a perpetuidad por la «sospechosa» - por lo baja- cifra de 5.000 ducados cada uno, los dos oficios de Visitador de Armadas y Flotas de la Casa de Contratación. ${ }^{86}$ Probablemente esa doble operación debió ser un buen negocio particular para el propio conde de Castrillo pues en 1697 los poseedores de ambos cargos serían denunciados por el propio fiscal del Consejo de Indias por «lesión enormísima» en la perpetuación de los mismos, es decir, por haberlos adquirido por un precio muy por debajo de lo que realmente valían, quedando de este modo perjudicados - lesionados - los intereses de la Corona.$^{87}$ En todo caso, dicha demanda - de la que serían finalmente exonerados- y que venía a acusar de delito al comprador, bien pudiera haber sido fruto de la diferencia entre la cantidad abonada por ambos compradores y el dinero ingresado realmente en la receptoría del Consejo de Indias. ${ }^{88}$

85 Fayard, 1982, 144.

86 AHN, Estado, 2312.

87 AGI, Escribanía, 1047C.

88 Andújar Castillo, 2013, 8-9. 


\section{La distribución del dinero}

Por lo general, todas las empresas venales que tuvieron lugar a lo largo del siglo XVII encontraron su legitimación perfecta en las urgencias de las guerras, omnipresentes durante toda la centuria, pero como hemos mostrado en otro estudio, precisamente relativo al período de Olivares, no todo el dinero recaudado se aplicó a tal fin, antes al contrario, al oneroso gasto cortesano, y dentro de él, a la obra del palacio del Buen Retiro. Para proteger la imagen del la monarquía de las acusaciones de despilfarro en la construcción del palacio no se utilizó ninguna renta ordinaria de la Real Hacienda. La consecuencia fue que los dos millones y medio de ducados que según Elliott y Brown costó la construcción se obtuvieron de medios extraordinarios. ${ }^{89}$ Estos ingresos extraordinarios coincidían con los anteriormente referidos «efectos de Indias», es decir, descaminos, penas de Cámara, cartas de naturaleza, ventas de perdones y, por supuesto, también la venta de oficios. ${ }^{90}$

No obstante, es preciso distinguir entre la distribución del dinero recaudado de «efectos de Indias» por parte del Consejo de Indias y el que había negociado el conde de Castrillo. El primero, como señalamos más arriba, se destinó a lo que podríamos denominar como gastos corrientes del Consejo, o lo que es lo mismo, pagos de salarios, ayudas de costa, pago de mercedes pecuniarias consignadas sobre la tesorería del Consejo, pensiones a viudas, limosnas a conventos y un numeroso conjunto de gastos menores. Nada que ver pues con la aplicación del dinero que había ingresado el conde de Castrillo en su especial tesorería.

Aunque el destino del dinero recaudado por Castrillo precisaría de por sí una monografía, podemos avanzar que la distribución del mismo, de la cual se ocupó personalmente el conde, siguiendo órdenes superiores, tuvo variadas aplicaciones. El grueso de lo recaudado se destinó a pagar a los asentistas que habían hecho préstamos al rey. Se trataba siempre de pagos a cuenta de sumas de mayor cuantía correspondientes a dichos asientos. Los nombres de asentistas italianos y portugueses como Francisco María Piquinotti, Duarte Fernández, Carlos Strata, Lelio Imbrea, Jorge de Paz Silveira, entre otros, figuran entre los destinatarios de los caudales de ventas de oficios. ${ }^{91}$ Cualquier análisis de las cuentas de la «data» del receptor del

89 Brown y Elliott, 2003, 104.

90 Gil Martínez, 2015a.

91 Todos ellos se encuentran muy bien documentados en la obra de Sanz Ayán, 2013. 
Consejo de Indias, que las tenía separadas de las del Consejo, revela el sinfín de conceptos de gasto a los que se aplicaba el dinero. Como muestra pueden anotarse las siguientes: pagos de salarios de criados reales; ayudas de costa a aristócratas que habían recibido mercedes pecuniarias del rey que no encontraban consignación en otras rentas, pagos por portes desde Sevilla de regalos que se recibían desde Indias — carey, quitasoles enviados desde La Habana- y, en suma, un copioso listado de capítulos de gasto cortesano. ${ }^{92}$

Por su reiteración, amén de los caudales que tuvieron como destino las obras del Buen Retiro, también cabe significar los gastos en las obras del palacio de la Zarzuela, tales como pagos a unos marmolistas por la chimenea de jaspe de San Pablo, a los que construían el estanque, al fontanero que se ocupaba del encañado del palacio, así como la compra de diversos objetos para el adorno de ambos palacios. En ese sentido, no es posible dejar de mencionar los 163.200 maravedíes que por libranza del conde de Castrillo se pagaron a la viuda del duque de Lerma por el «precio de doce cuadros países con figuras y con sus marcos dorados que se compraron para Su majestad en la almoneda del dicho duque y se pusieron en Buen Retiro en la Sala de las Consultas». ${ }^{93}$

Con anterioridad a la tarea de Castrillo, las comisiones que beneficiaron expedientes de Indias también vieron cómo el dinero recaudado se destinaba a gastos múltiples y entre ellos a los palacios reales. De la Junta particular que formaron en 1632-1633 el duque de Medina de las Torres, Busto de Bustamante y Lorenzo Ramírez de Prado, y que como hemos visto produjo unos ingresos muy inferiores a los que iba a obtener Castrillo, su producto salió hacia gastos tan diversos como fueron pagos al factor general Bartolomé Spínola a cuenta de 55.000 ducados que había de proveer de los 300.000 escudos de la factoría de los estados de Flandes; al guardajoyas de la reina para «cosas que le están mandadas del servicio de S.M. para adorno del Buen Retiro»; pago de un bufete de plata, de un brasero, etcétera. Incluso se fueron pagando deudas de dinero adelantado por financieros para el ornato del palacio real, como los 25.000 reales de plata que se abonaron en febrero de 1634 a «Juan Lucas Palavesin del resto del precio que este hubo de pagar por la tapicería de oro y seda que compró el dicho duque de don Fadrique de Toledo que se puso en el Buen Retiro para el servicio de Su Majestad por cuyo mandado se compró». ${ }^{94}$ De todo lo que fueron pagos rela-

92 AGI, Contaduría, 64.

93 Idem.

94 AGI, Contaduría, 76. 
cionados con la construcción y adorno del palacio del Buen Retiro se ocuparon personalmente el duque de Medina de las Torres, yerno del conde-duque de Olivares, el propio conde de Castrillo y Jerónimo de Villanueva.

Por último, entre esas múltiples aplicaciones que tuvo el dinero de los efectos de Indias, reseñamos las partidas que fueron a parar a lo que debieron ser los «gastos secretos» del rey. De cuantas tesorerías funcionaban en la monarquía, tan solo la de gastos secretos no debía dar cuenta ni razón de algunos de los pagos que realizaba, aunque eso sí, siempre precediendo orden del monarca. Más arriba hemos visto cómo Jerónimo de Villanueva, Protonotario de Aragón, fue destinatario de una partida de 23.429 ducados para el pago de un asiento que había hecho con Carlos Strata. Seguramente se trataría de un préstamo hecho por Strata a la tesorería de gastos secretos en la que, precisamente, el dinero salía siempre a las órdenes del Secretario del Despacho, Jerónimo de Villanueva, quien tenía entre sus atribuciones la de atender privativamente la administración de los gastos secretos. ${ }^{95}$ Detrás de dichas órdenes es más que probable que estuviera el conde-duque de Olivares, de quien Villanueva era, en palabras de Elliott, su «mano derecha». ${ }^{96}$

\section{Conclusión}

Cambiar mercedes por dinero fue durante todo el Antiguo Régimen una medida polémica cuya aplicación varió en función de coyunturas y de las necesidades de numerario de la monarquía. La etapa de Olivares fue una fase álgida de ventas de cargos, especialmente de aquellos que se iban a ejercer en Indias, con los de hacienda a la cabeza, pero también los de la Casa de Contratación y los apreciados maestrajes de plata de la Carrera de Indias. Habría que esperar al reinado de Carlos II para que al mercado venal americano se sumaran los puestos de justicia y gobierno.

En esta aportación hemos mostrado cómo el fenómeno del valimiento del conde-duque de Olivares tuvo una estrecha relación con la forma en que se orquestó la almoneda de oficios y mercedes. Que el conde de Castrillo, a espaldas del Consejo que presidía, llevase un volumen de ventas como el que hemos referido, nos lleva necesariamente a tener que replantearnos el papel de las instituciones de gobierno de las Indias. La venalidad sirvió a Olivares no solo como fuente de ingresos extraordinaria para la monarquía,

95 Seiz Rodrigo, 2010, 123.

96 Elliott, 1998, 355. 
sino también como un poderoso instrumento para aumentar su control sobre las instituciones de gobierno a través de sus más afectos colaboradores.

El papel del Consejo como vía para la provisión de cargos quedó por tanto prácticamente anulado no solo por el hecho de que el dinero sustituyó al mérito a la hora de designar a los oficiales, sino porque fue una única persona, Castrillo, quien negoció todos los detalles de las operaciones. El enorme poder que el aristócrata llegó a amasar en sus manos supone también un elemento fundamental para entender el gobierno de los territorios americanos en esta época. La opinión del sínodo de letrados pesó muy poco en el ánimo del rey, quien constantemente respaldó las propuestas de Castrillo, aun en contra del parecer del Consejo. Se trata por tanto de una singular variación del fenómeno del valimiento tal y como lo conocemos, pues si bien Castrillo no llegó a tener con el monarca la misma relación personal que Olivares, sí que gozó de una amplísima libertad para hacer y deshacer en todo lo referente a los territorios americanos.

Precisamente este amplio margen de maniobra que Felipe IV otorgó a Castrillo es quizá uno de los mejores ejemplos de absolutismo, pues ni siquiera la propia legislación promulgada durante el reinado sirvió de barrera al poder regio cuando se puso en marcha la política venal. No obstante se trata de un proceso con una doble implicación, pues aunque a corto plazo supuso una concentración de poder en los círculos más cercanos al monarca, las ventas de oficios tuvieron implicaciones a más largo plazo, reduciendo considerablemente el margen de poder del soberano. En todo caso, en el ciclo venal abierto por el valimiento de Olivares las ventas de oficios no fueron únicamente un expediente con interés fiscal, sino que sirvieron también para reforzar las posiciones afines al conde-duque. Queda por estudiar si la venalidad desempeñó este mismo papel en otros periodos o si, por el contrario, la primera mitad del reinado de Felipe IV constituye una excepción.

Asimismo, en las páginas precedentes, amén de poner de manifiesto el poder acumulado por Castrillo en la venta de oficios de Indias, hemos mostrado problemas conexos que precisan de investigaciones de mayor calado. La aplicación del dinero recaudado, no solo para la guerra sino para el gasto cortesano, con la construcción de los palacios reales a la cabeza, merece un análisis en profundidad. Mantener, e incluso aumentar, el nivel de gasto cortesano es un elemento que se encuentra estrechamente relacionado con el valimiento, pues la posición del privado dependía de la comodidad del soberano. Del mismo modo, un estudio sobre las relaciones entre Castrillo y los compradores de cargos americanos, en especial en torno a las cuantías 
«oficiales» abonadas y las que pudieron ir a bolsillos privados nos acerca a plantear el problema de la corrupción o, si se nos permite la redundancia, de los «beneficios privados del privado». Sea como fuere, ambos problemas, aplicación del dinero y posible corrupción en las negociaciones de ventas de cargos, son cuestiones que precisarán de un estudio más global que analice la figura de Castrillo como gran artífice de la enajenación de cargos para ejercer en América y también en España.

Recibido el 20 de abril de 2015 Segunda versión el 30 de septiembre de 2015

Aceptado el 8 de octubre de 2015

\section{Referencias bibliográficas}

Álvarez Nogal, Carlos, «Los maestres de plata durante el reinado de Felipe IV. Nombramientos y beneficios», en Gutiérrez Escudero, Antonio (coord.), Ciencia, economía y política en Hispanoamérica colonial, Sevilla, CSIC, 2000, 139-160.

Amadori, Arrigo, «Privanza, patronazgo y fiscalidad indiana en la corte de Madrid durante el reinado de Felipe IV», Revista Complutense de Historia América, 34, Madrid, 2008, 63-84.

Amadori, Arrigo, Política americana y dinámicas de poder durante el valimiento del conde-duque de Olivares (1621-1643), Tesis doctoral, Madrid, Universidad Complutense, 2011 (disponible en http://eprints.ucm.es/14054/1/ T33303.pdf).

Andrés Ucendo, José Ignacio y Lanza García, Ramón, «Estructura y evolución de los ingresos de la Real Hacienda de Castilla en el siglo XVII», Studia Histórica Historia Moderna, 32, Salamanca, 2008, 147-190.

Andrien, Keneth, «The sale of Fiscal Offices and the decline of Royal Autority in the Viceroyalty of Peru, 1633-1700», The Hispanic American Historical Review, 1, 1982, 49-72.

Andújar Castillo, Francisco, Necesidad y venalidad. España e Indias 1704-1711, Madrid, Centro de Estudios Políticos y Constitucionales, 2008.

Andújar Castillo, Francisco, «Los contratos de venta de empleos en la España del Antiguo Régimen», en Andújar Castillo, Francisco y Felices de la Fuente, María del Mar (eds.), El poder del dinero: Ventas de cargos y honores en el Antiguo Régimen, Madrid, Biblioteca Nueva, 2011, 63-82.

Andújar Castillo, Francisco, «La litigiosidad en torno a las ventas de oficios perpetuos en la Castilla del siglo XVII», Les Cahiers de Framespa, 12, 2013, 2-14.

Andújar Castillo, Francisco, «La Casa de Contratación de Sevilla y la venalidad de los cargos (1634-1717)», en Núñez Roldán, Francisco; Gamero Rojas, Mercedes, Entre lo real y lo imaginario: estudios de historia moderna en 
homenaje al prof. León Carlos Alvarez Santaló, Sevilla, Universidad de Sevilla, 2014, 47-73.

Andújar Castillo, Francisco y Gil Martínez, Francisco, «Los indultos al comercio durante la Guerra de Sucesión: la Junta de Indultos», en Iglesias Rodríguez, J.J.; Pérez García, R.M. y Manuel F. Fernández Chaves, M.F. (eds.), Comercio y cultura en la Edad Moderna. Comunicaciones de la XIII Reunión Científica de la Fundación Española de Historia Moderna, Sevilla, Editorial Universidad de Sevilla, 2015, 1109-1121.

Berthe, Jean Pierre y Calvo, Thomas, Administración e imperio: el peso de la monarquía hispana en sus Indias (1631-1648), Zamora, Michoacán, Fideicomiso Teixidor, 2011.

Bertrand, Michel, Grandeza y miseria del oficio. Los oficiales de la Real Hacienda de la Nueva España, siglos XVII y XVIII, México, El Colegio de Michoacán, 2011.

Brown, Jonathan y Elliott, John H., Un palacio para el rey: El Buen Retiro y la corte de Felipe IV, Madrid, Taurus, 2003.

Burgos Lejonagoitia, Guillermo, Gobernar las Indias. Venalidad y méritos en la provisión de cargos americanos, 1701-1746, Almería, Universidad de Almería, 2015.

Burkholder, Mark A. y Chandler, D.S., De la impotencia a la autoridad: la Corona española y las Audiencias en América, 1687-1808, México, Fondo de Cultura Económica, 1984.

Campos Sánchez-Bordona, María Dolores, «Fundación y construcción del Colegio de la Compañía de Jesús en Villafranca del Bierzo», Tierras de León. Revista de la Diputación Provincial, 95-96, León, junio-septiembre 1994, 59-80.

Díaz Blanco, José Manuel, «La extinción de las naturalezas en la Carrera de Indias (un episodio de la caída del conde duque de Olivares)», en Álvarez Santaló, Luis Carlos (ed.), Estudios de Historia Moderna en homenaje al profesor Antonio García-Baquero, Sevilla, Universidad de Sevilla, 2009, 321-336.

Díaz Blanco, José Manuel, «En torno a la ocultación de la venalidad: Las naturalezas en la Carrera de Indias (1621-1643)», en Andújar Castillo, Francisco y Felices de la Fuente, María del Mar (eds.), El poder del dinero: Ventas de cargos y honores en el Antiguo Régimen, Madrid, Biblioteca Nueva, 2011, 314-328.

Domínguez Ortiz, Antonio, «La concesion de naturalezas para comerciar en indias durante el siglo XVII», Revista de Indias, 19, 1959, 227-239.

Domínguez Ortiz, Antonio, «La quiebra de Domingo Ypeñarrieta, Maestre de Plata», Archivo Hispalense, 68, Sevilla, 1985, 405-418.

Elliott, John, El conde-duque de Olivares: el político en una época de decadencia, Barcelona, Crítica, 1998.

Fayard, Janine, Los miembros del Consejo de Castilla (1621-1746), Madrid, Siglo Veintiuno, 1982. 
García Hernán, Enrique, Consejero de ambos mundos: vida y obra de Juan de Solórzano Pereira (1575-1655), Madrid, Mapfre, 2007.

Gil Martínez, Francisco, «Construir un palacio en tiempos de guerra. La financiación del Buen Retiro (1634-1635)», en Labrador Arroyo, Félix (ed.), II Encuentro de jóvenes investigadores en Historia Moderna. Líneas recientes de investigación en Historia Moderna, Madrid, Universidad Rey Juan Carlos, 2015a, 1185-1198.

Gil Martínez, Francisco, «Apuntes para el análisis de redes en Historia: las relaciones interpersonales», en Rey Castelao, Ofelia y Suárez Golán, Fernando (eds.), Los vestidos de Clío. Métodos y tendencias recientes de la historiografía modernista española (1973-2013), Santiago de Compostela, Universidade de Santiago de Compostela, 2015b, 761-772.

Gil Martínez, Francisco, «De la negociación a la coerción: la recaudación del donativo de 1635», Studia Historica. Historia Moderna, 37, Salamanca, 2015c, 211-234.

Giménez Carrillo, Domingo Marcos, «La venta de hábitos de las Órdenes Militares en el siglo XVII: Entre la ocultación y el delito de simonía», en Andújar Castillo, Francisco y Felices de la Fuente, María del Mar (eds.), El poder del dinero: Ventas de cargos y honores en el Antiguo Régimen, Madrid, Biblioteca Nueva, 2011, 301-313.

Gómez Rivero, Ricardo, «Consejeros de Órdenes. Procedimiento de designación (1598-1700)», Hispania, 214, 2003, 657-744.

Jiménez Moreno, Agustín, «Honores a cambio de soldados, la concesión de hábitos de las Órdenes Militares en una coyuntura crítica: la Junta de Hábitos (16351642)», en Soria Mesa, Enrique; Bravo Caro, Juan Jesús y Delgado Barrado, José Miguel (eds.), Las élites en la época moderna: la Monarquía Española. Volumen III: Economía y poder, Córdoba, Universidad de Córdoba, 2009, 155-171.

Jiménez Moreno, Agustín, Nobleza, guerra y servicio a la Corona: los caballeros de hábito en el siglo XVII, Madrid, Universidad Complutense, 2011.

Mazín, Óscar, «Ascenso político y "travestismo" en la corte del rey de España: un episodio de la trayectoria de don García de Haro, segundo conde de Castrillo», Pedralbes Revista de Historia Moderna, 32, 2012, 79-126.

Muro Romero, Fernando, «El "beneficio" de oficios públicos con jurisdicción en Indias. Notas sobre sus orígenes», Anuario de Estudios Americanos, 35, Sevilla, 1978, 311-360.

Parry, John, The Sale of Public Office En the Spanish Indies under the Hapsburgs, Los Angeles, University of California Press Berkeley, 1953.

Román, Alberto Yalí, «Sobre alcaldías mayores y corregimientos en Indias. Un ensayo de interpretación», Jahrbuch für Geschichte Lateinamerikas, 9, 1972, 1-39. 
Ruiz Rivera, Julián y Sanz Tapia, Ángel (eds.), La venta de cargos y el ejercicio del poder en Indias, León, Universidad de León, 2007.

Sanz Ayán, Carmen, Los banqueros de Carlos II, Valladolid, Universidad de Valladolid, 1989.

Sanz Ayán, Carmen, Los banqueros y la crisis de la Monarquía Hispánica de 1640, Madrid, Marcial Pons, 2013.

Sanz Ayán, Carmen, Un banquero en el Siglo de Oro. Otavio Centurión, el financiero de los Austrias, Madrid, La Esfera de los Libros, 2015.

Sanz Tapia, Ángel, «Cargos políticos beneficiados en Hispanoamérica bajo Carlos II», en Gutiérrez Escudero, Antonio (coord.), Ciencia, economía y política en Hispanoamérica colonial, Sevilla, CSIC, 2000, 161-180.

Sanz Tapia, Ángel, «La venta de oficios de hacienda en la Audiencia de Quito (1650-1700)», Revista de Indias, 63, Madrid, 2003, 633-648.

Sanz Tapia, Ángel, ¿Corrupción o necesidad? La venta de cargos de Gobierno americanos bajo Carlos II (1674-1700), Madrid, CSIC, 2009.

Sanz Tapia, Ángel, «Provisión, beneficio y venta de oficios americanos de hacienda (1632-1700)», Revista Complutense Historia de América, 37, Madrid, 2011, 145-172.

Sanz Tapia, Ángel, «La justicia en venta. El beneficio de cargos americanos de Audiencia bajo Carlos II (1683-1700)», Anuario de Estudios Americanos, 69, Sevilla, 2012, 63-90.

Schäfer, Ernst, El Consejo Real y Supremo de las Indias, Valladolid, Junta de Castilla y León, 2003.

Seiz Rodrigo, David, La disimulación honesta: los gastos secretos en el reinado de Felipe IV. Entre la razón de estado y la merced cortesana, Madrid, Endymion, 2010.

Tomás y Valiente, Francisco, «Notas sobre la venta de oficios públicos en Indias» en III Congreso del Instituto Internacional de Historia del Derecho Indiano, Madrid 17-23 de enero de 1972: actas y estudios, Madrid, Instituto Nacional de Estudios Jurídicos, 1973, 377-422.

Tomás y Valiente, Francisco, La venta de oficios en Indias (1492-1606), Madrid, Instituto Nacional de Administración Pública, 1982.

Vila Vilar, Enriqueta, «Los maestres de plata: un resorte de poder en el comercio con Indias», en Sarabia Viejo, María Justina (ed.), De Puebla de los Ángeles a Sevilla. Homenaje al Dr. José Antonio Calderón Quijano, Sevilla, Universidad de Sevilla, 1997, 119-131.

Vila Vilar, Enriqueta, «Algo más sobre el fraude en la Carrera de Indias: práctica conocida, práctica consentida», en Fisher, John R. (ed.), Actas del XI congreso internacional de AHILA, Liverpool, University of Liverpool, 1998, 27-43.

Volpini, Paola, «Las Allegationes Fiscales (1642-1645) de Juan Bautista Larrea», Revista de Historia Moderna. Anales de la Universidad Alicante, 15, 1996, 465-502. 